\title{
Apparent water loss prevention using modern measurement tools
}

\author{
Joanna Gwoździej-Mazur ${ }^{1, *}$ \\ ${ }^{1}$ Department of Environmental of Engineering Systems, Bialystok University of Technology, 15-351 \\ Bialystok, ul.Wiejska 45E, Poland
}

\begin{abstract}
The problem of discrepancies in balancing housing water meters indications in relation to the main water meters in multihousing/family building is well known to both, property owners as well as to water supply and sewage companies. The article presents the results of research in the field of flows which are characteristic to the water supply connection in school complexes and the Conference and Training Center. using modern monitoring systems. Studies have shown that it is possible to eliminate the apparent loss occurring especially at night, resulting mainly due to improper selection/choice of the measuring device, which is the main water meter.
\end{abstract}

\section{Introduction}

Measuring instruments serve for measurement of a given physical quantity, processing of the information acquired from measurement and transferring this information to the observer. They are intended for performing a specific task under specific working conditions and in keeping with planned requirements. The most important requirement that must be met by measuring instruments is preservation of set metrological characteristics.

One of the reasons for apparent losses in water supply systems is the improper selection of the metering device on the water service line. The water meter should be selected on the basis of the hydraulic parameters in the pipe, i.e. nominal and maximum values of the volume stream of flowing water. For this purpose, the operating range of the water meter during the day must be determined precisely, preferably on the basis of actual measurements and service line monitoring.

The goal of this paper was to assess whether the installation of static, electromagnetic water meters will contribute to limiting apparent losses as well as to determine the structure of water consumption according to characteristic flow intervals describing the accuracy of water meters

\section{Accuracy classes of water meters}

Based on standard PN-ISO 4064, four accuracy classes of water meters have been introduced: A, B, C and D, and a characteristic flow rate for a given diameter has been

*Corresponding author: j.mazur@pb.edu.pl 
determined for each of them. However, this classification proved to be insufficient, and large differences between water meters were present within the same class, so in practice, this data did not facilitate selection [1,2].

Companies producing water meter attempted to solve this problem by providing additional parameters not required by the standard, but over time, the reliability of certain declarations was called into question.

Only a change of requirements for these devices that would account for technical progress and differences in design could solve this situation. For this purpose, standard PNEN 14154 was used as the basis for requirements introduced into the Directive of the European Parliament and of the Council on measuring instruments (MID). Although companies producing water meter can still declare parameters characterizing water meters, this data is now verified.

The manufacturing process is also verified for repeatability of manufacturing quality equal to that of the item tested by the notified body so that a certificate can be issued not just for tested items.

Starting from 2017, Companies producing water meter should only apply water meter assessment in compliance with the MID directive. The MID directive also introduced different determinations of characteristic flows and terminology than before, i.e. [2]:

$\mathrm{Q}_{1}$ - minimum flowrate - the lowest flowrate at which the water meter provides indications that satisfy the requirements concerning the maximum permissible errors (MPEs);

$\mathrm{Q}_{2}$ - transitional flowrate - the transitional flowrate is the flowrate value occurring between the permanent and minimum flowrates, at which the flowrate range is divided into two zones, the 'upper zone' and the 'lower zone'. Each zone has a characteristic MPE;

$\mathrm{Q}_{3}$ - permanent flowrate - the highest flowrate at which the water meter operates in a satisfactory manner under normal conditions of use, i.e. under steady or intermittent flow conditions. The numerical value of permanent flowrate $\mathrm{Q}_{3}\left[\mathrm{~m}^{3} / \mathrm{h}\right]$ is to be selected from among the following values: $1.0 ; 1.6 ; 2.5 ; 4.0 ; 6.3 ; 10 ; 16 ; 25 ; 40 ; 63 ; 100 ; 160 ; 250 ; 400$; $630 ; 1000 ; 1600 ; 2500 ; 4000 ; 6300$. In the transitional period, the following values are permitted: $1.5 ; 3.5 ; 6 ; 15 ; 20$;

$\mathrm{Q}_{4}$ - overload flowrate - The overload flowrate is the highest flowrate at which the meter operates in a satisfactory manner for a short period of time without deteriorating.

Water meter classes according to the MID directive are presented in the Figure below.

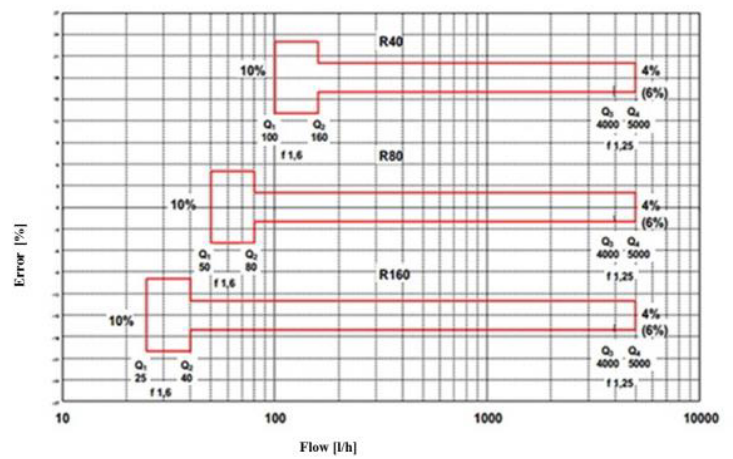

Fig. 1. Water meter classes according to MID [2]. 
According to legal regulations, an $\mathrm{R}$ value corresponding to different metrological classes of water meters is to be determined, where [2]:

$$
\mathrm{Q}_{3}=\mathrm{Q}_{4} / 1.25
$$

and:

$$
\mathrm{R}=\mathrm{Q}_{3} / \mathrm{Q}_{1}
$$

In relation to this, determining and selecting the proper metrological class of water meters of a given size is related to flowrate $\mathrm{Q}_{1}$, which determines the boundary between measuring ranges characterized by different maximum permissible error values. Therefore, after determining the size of a water meter, the metrological class or minimum flowrate characterizing the water meter must be determined. Together, these two elements are to minimize apparent losses to below $1 \%$ (assumed at least during the initial period of measurement) [3-5].

In turn, metrological requirements according to the MID directive are as follows: the maximum permissible error in the lower range of flowrates from $\mathrm{Q}_{1}$ inclusively to $\mathrm{Q}_{2}$, not including $\mathrm{Q}_{2}$, is $\pm 5 \%$ (cold, warm and hot water), the maximum permissible error in the upper range of flowrates from $\mathrm{Q}_{2}$ inclusively to $\mathrm{Q}_{4}$, not including $\mathrm{Q}_{4}$, is $\pm 2 \%$ (cold water) and $\pm 3 \%$ (warm and hot water).

\section{Causes of losses and methods of preventing losses in a water supply system}

When analyzing the causes of water losses in internal systems, water losses are to be divided into two categories - actual losses and apparent losses [6-9].

Actual losses are mostly the result of a poor technical condition of the water supply system. Failures of a system's pipes, joints and fittings have the greatest impact on the size of these losses.

Apparent losses are mainly the result of low accuracy of measurement of the volume of flowing water and non-simultaneity of readings of devices registering the amount of water supplied to the system (main water meter) and consumed by recipients (sub-meters on premises) $[3,7,10,11]$.

Making an accurate estimate of apparent losses is a very difficult task, and frankly speaking, practically impossible. This is due to the lack of a constant value of errors in measuring devices. According to legal regulations, metering devices must be within the margin of error, which is $\pm 2 \%$ or $\pm 5 \%$ for water meters (depending on flowrate) $[12,13]$.

When taking measures intended to reduce losses occurring in water supply networks and systems, both actual and apparent losses must be accounted for. Based on literature states, experience and direct contact with administrators and residents of housing cooperatives and communities as well as with recipients in public buildings, additional methods of preventing water losses in internal systems can be proposed $[3,6-8,10]$ :

- metering of all premises and intake points. This should be the starting point of organizing water management in a building. As long as there is even one apartment billed on a lump-sum basis in a given building, balancing water consumption is out of the question,

- replacement of water meters (sub-meters) with meters of a higher metrological class, i.e. with greater accuracy of measurement and lower start-up threshold. Volumetric water meters that maintain their metrological class in every position of installation are particularly suitable for residential buildings. This is very significant, since it is often not possible to install a water meter in a horizontal position in buildings of this type due 
to lack of space. A volumetric water meter also does not require straight segments before and after the water meter,

- keeping water meter replacement deadlines, i.e. making sure verification periods are observed. According to regulations, most water meters have a five-year verification period, after which they should be replaced. A water meter that has been in operation for a longer period does not necessarily have to give incorrect readings, but it is at greater risk of e.g. deposition of various contaminants or scale found in water, and thus, the probability of inaccuracy of measurement increases,

- mounting of radio transmitters on water meters. A frequent cause of differences in a building's water balance is the so-called "time-space" phenomenon, based on the fact that readings of individual sub-meters are given by recipients after a certain interval of time. One recipient may give a reading earlier because they are going on a trip at the end of the month, and another may give their reading later, simply because they forgot. Moreover, water meter readings are given with varying accuracy. Recipients may round the number of $\mathrm{m}^{3}$ down or up. When there are several dozen water meters, a significant difference may arise in comparison to the main water meter. A radio system makes it possible to read all water meters at the same time and with the same, precise accuracy, as well as to save data e.g. at the end of every month,

- elimination of leaks at intake points. A large leak that floods a bathroom is removed immediately. However, small leaks are the most dangerous, since we either disregard them (leaking faucet) or cannot see them at all with the naked eye (leaking flush). Such leaks are also often not registered by sub-meters, but the main water meter is capable of metering them,

- overhauls of the internal water supply system. A building's water supply system should be modernized periodically. This makes it possible to eliminate old, frequently corroded, pipes and leaking joints, thus contributing to reduction of losses.

- maintenance of the proper water pressure in the internal system, particularly in the case of pressure spikes in the water supply network, and it is a good solution to install a pressure reducer on the service pipe to prevent an uncontrolled pressure increase in the internal system. Higher pressure will result in greater leakage.

\section{Methodology of research}

The object of conducted studies were characteristic flows in the water supply service pipe as well as analysis of the structure of water consumption in selected public buildings. Installation of the proper water meters and digital registration were possible thanks to the cooperation of the water company in Gołdap and the Sensus company. The process began with preliminary selection of buildings, after which a site survey was conducted for the purpose of detailed characterization of selected buildings in the scope of: building size (number of guests, students, services rendered, type and location of main water meter, etc.). Ultimately, two buildings were selected for study: pre-secondary school complexes and the Conference and Training Center. Flowrate measurements on the water service pipe covered a period of 46 days. A static, electromagnetic IPERL water mater from the Sensus company was used for tests. Residual magnetic field technology was applied in the water meter, ensuring a linear measuring range even at the lowest flowrate values. The magnetic field acting on water flowing through the measuring segment creates electrical voltage proportionally to its flowrate (principle of magnetic induction in flow measurement). 


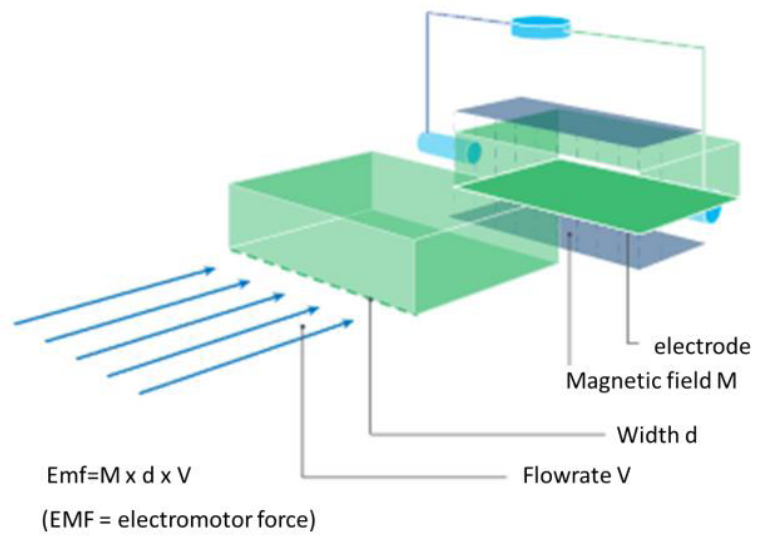

Fig. 2. Principle of magnetic induction in the IPERL water meter [14].

IPERL is equipped with an integrated low-power radio module operating at a frequency of $868 \mathrm{MHz}$ or $433 \mathrm{MHz}$. Communication is provided by innovative "walk-by" or "driveby" billing reading technology as well as by the capability of querying a device to obtain up to 2880 points with registered data. The principle of operation is based on reception of impulses transmitted by the transmitter installed on water meters by means of the Sensus Interface Radio Tool (SIRT), which is followed by registration and saving of these impulses using specialized software, which enables interpretation and analysis of read results later on.

\section{Analysis of test results}

The first studied case was a public building, namely a public school. Due to the nature of the buildings as well as large differences in water consumption over the course of a day, instant water flowrates were checked in the water service pipe. Among other things, minimum flowrates were registered, and an illustration of minimum flowrates is presented in Fig. 3.

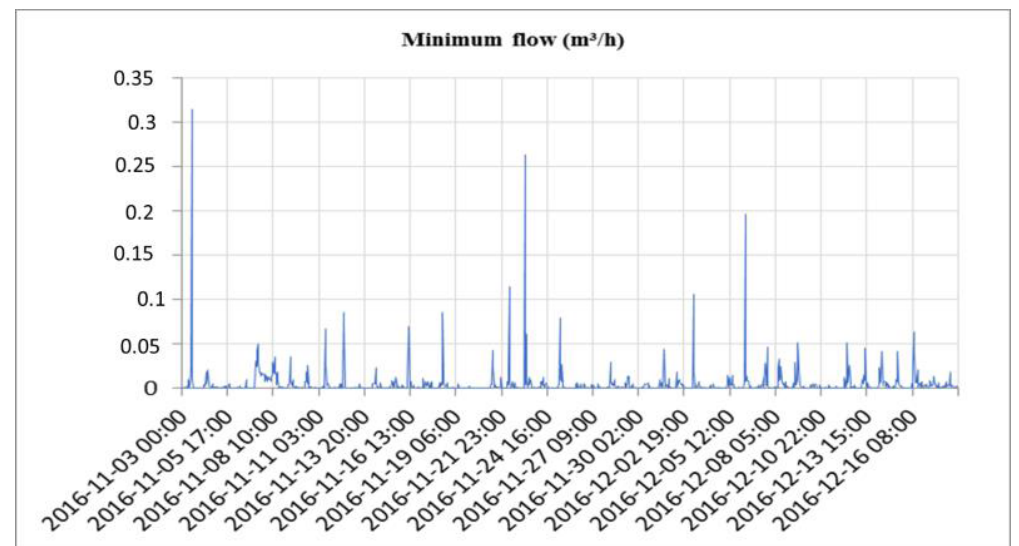

Fig. 3. Minimum water flowrate in the water service pipe to the complex of pre-secondary schools. 
Minimum flowrates reflected the nature of the building, besides the fact that peaks were twice as high. Moreover, registration made it possible to state that the building's internal water system is serviceable, since the water period did not register any flows during the night hours. An addition site visit of the building was conducted and employees were interviewed in order to explain repeating elevated flow values on the water service line (03/11/2016 - time 2:00 P.M., 23/11/2016 - time 8:00 A.M., 06/12/2016 - time 10.00 A.M.). The repeating phenomenon is most probably related to maintenance of equipment installed in one of the building's workshops.

Characteristic intervals for different types and classes of water meters were selected for data analysis in order to illustrate water consumption in the studied building. Results based on monitoring are presented in table 1.

Table 1. Percentage of the minimum water flowrate consumed per hour in the complex of pre-secondary schools.

\begin{tabular}{|c|c|}
\hline $\begin{array}{c}\text { Flowrate } \\
\mathrm{m}^{3} / \mathrm{h}\end{array}$ & $\begin{array}{c}\text { Total } \\
\%\end{array}$ \\
\hline$<0.01$ & 90.64 \\
\hline $0.01-0.02$ & 4.61 \\
\hline $0.02-0.03$ & 2.23 \\
\hline$>0.03$ & 2.53 \\
\hline
\end{tabular}

The presented analysis of the hourly percentage of minimum flowrate consumed shows that flowrates from the interval from 0.00 to 0.02 had the greatest total share in minimum flowrates. It turned out that not all minimum flows were registered (apparent loss) until the time at which the water meter used for tests was replaced.

Another building which flowrates in the water service pipe were analyzed in detail was the Conference and Training Center. The distribution of minimum flowrates proved to be interesting. An example is shown in Fig. 4. Minimum flowrates are nearly continuously present in the studied building and make up a very large share of the structure of water consumption. The water meter registered an alarm signaling a water leak almost every day over the course of the period subject to analysis. It can be stated with high probability that the building contains intake points from which water is leaking in an uncontrolled manner. 


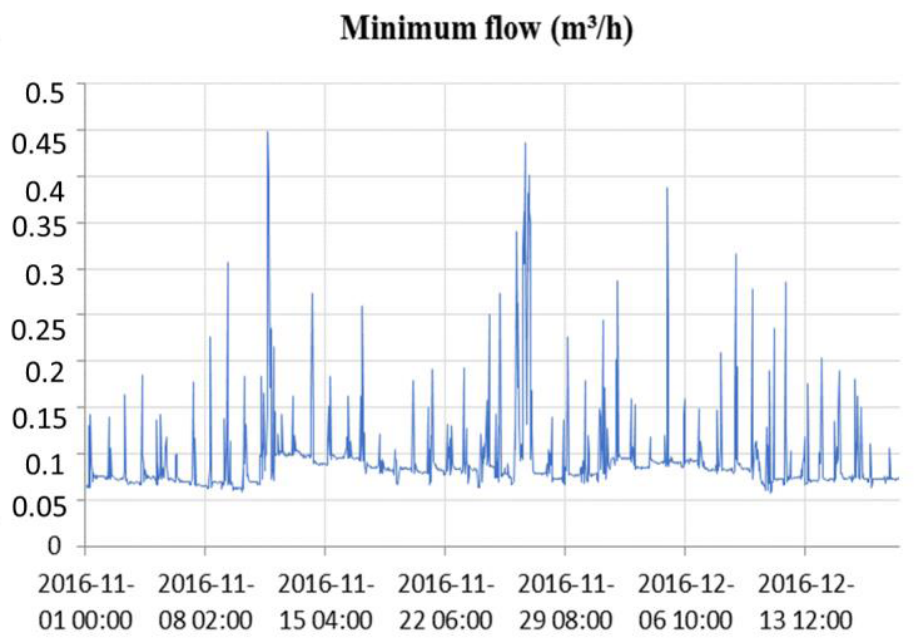

Fig. 4. Minimum water flowrate on water service pipe to the Conference and Training Center.

Due to the unserviceable water system in the building, the percentage distribution illustrating the class of water meters for both minimum and maximum flowrates on the water service pipe was investigated in detail (Table 2, Table 3).

Table 2. Percentage of the minimum water flowrate consumed per hour in the Conference and Training Center.

\begin{tabular}{|c|c|c|c|c|c|c|c|}
\hline $\begin{array}{c}\text { Flowrate } \\
\mathrm{m}^{3} / \mathrm{h}\end{array}$ & $<0.7$ & $0.07-0.1$ & $0.1-0.3$ & $0.3-0.5$ & $0.5-1.0$ & $1.0-2.0$ & $>2.0$ \\
\hline $\begin{array}{c}\text { Total } \\
\%\end{array}$ & 3.27 & 29.57 & 15.90 & 13.37 & 26.60 & 9.21 & 2.08 \\
\hline
\end{tabular}

Table 3. Percentage of the maximum water flowrate consumed per hour in the Conference and Training Center.

\begin{tabular}{|c|c|c|c|c|c|c|c|}
\hline $\begin{array}{c}\text { Flowrate } \\
\mathrm{m}^{3} / \mathrm{h}\end{array}$ & $<0.06$ & $\begin{array}{c}0.06- \\
0.07\end{array}$ & $\begin{array}{c}0.07- \\
0.12\end{array}$ & $0.12-0.2$ & $0.2-0.3$ & $0.3-0.4$ & $>0.4$ \\
\hline $\begin{array}{c}\text { Total } \\
\%\end{array}$ & 0.15 & 20.51 & 68.35 & 7.28 & 1.49 & 1.78 & 0.45 \\
\hline
\end{tabular}

Flowrates within the interval of $0.06-0.2 \mathrm{~m}^{3} / \mathrm{h}$ had the greatest total share in minimum flowrates. In total, they make up $96.14 \%$ of all minimum flowrates. High values of maximum flowrates do not occur too frequently, are predictable, and it can be said that they are of lesser significance in the studied building than minimum flowrates. Flowrates registered in the interval from 0.07 to $1.0 \mathrm{~m}^{3} / \mathrm{h}$ had the greatest share in the structure of maximum flowrates.

The example above shows that selecting a water meter is not an easy task. On one hand, a water meter must have a high metrological class in order to measure minimum flowrates, and on the other, it should also have the proper throughput, so that it can operate at maximum flowrates safely and without obstacle. 


\section{Summary}

By registering and analyzing actual hydraulic conditions in a given water service line in public buildings, or the minimum stream of water volume, their total share in intervals defining the accuracy of metering devices was determined. Knowing the structure of water consumption in water supply systems, it can be stated whether the main water meter was properly selected. This is of enormous significance, because a water meter that is too small for the given working conditions will be at risk of hydraulic overload, which will result in premature wear of the mechanism, while a water meter that is too large provides lesser accuracy at minimum water flows (apparent loss).

One of possible ways to minimize apparent losses is to upgrade metering instruments to achieve better and more accurate measurements

Currently, the technical norms used to determine designed flows on the water service line do not reflect actual flows, which provides a basis for stating that installing water meters on the water service line, equipped with flow recorders and a high $\mathrm{R}$ factor, will make it possible to limit apparent losses.

Digital registration of the stream of water volume in the water service line provides the most reliable results. Information obtained on the subject of the water distribution profile makes it possible to precisely determine designed flow and values not exceeding it, which is an important factor in selection of main water meters.

Studies have been carried out in the framework of working No. S/WBiIŚ/02/2014 and financed from the funds for science MNiSW.

\section{References}

1. PN-EN 14154-1:2007 Water meters - Part 1: General requirements.

2. Directive 2004/22/EC of the European Parliament and of the Council on measuring instruments (OJ EU L 135 of 31/03/2004, 1-80)

3. T. Cichoń, J. Królikowska, A. Królikowski, Gaz, Woda I Technika Sanitarna, 6 (2013)

4. P. Tuz, Rynek Instalacyjny, 5 (2009)

5. P. Tuz, Rynek Instalacyjny, 6 (2009)

6. Water Audits and Loss Control Programs. Manual of Water Supply Practices M36. 3rd ed. AWWA. 283 (2009)

7. M. Rimeika, R. Albrektien, The 9th International Conference ENVIRONMENTAL ENGINEERING, Vilnius, Lithuania (2014)

8. G. L. Richards, M. C. Jonson, S. L. Barfuss, J. Am. Water. Works. Ass. 105(5), (2010)

9. T. Cichoń, J. Królikowska, Ecol. Eng. 48 (2016)

10. F. Arregui, E. Cabrera, R. Cobacho, J. Gracia-Serra, Water Practice and Technology 1, 4 (2006)

11. W. Koral, Instal, 5 (2005)

12. J. Chudzicki, S. Sosnowski (Wydawnictwo Seidel-Przywecki, Warszawa 2005)

13. M. Kietniewski, W. Olszewski, E. Osuch-Pajdzińska (Oficyna Wydawnicza Politechniki Warszawskiej, 2016)

14. Materials company Sensus 